by

H. A. Saller

S. J. Paprocki

J. F. Delaney

This document is PUBCICLY RELEASABLE Bam Stede Authorizing Official Date: $1 \cdot 10-07$ CLASSIFICATION CANCELLED DATE For The Atomic Energy Commission Chiof, Deciassification Branch

August $3, \sqrt{9954}$

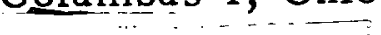




\section{DISCLAIMER}

This report was prepared as an account of work sponsored by an agency of the United States Government. Neither the United States Government nor any agency Thereof, nor any of their employees, makes any warranty, express or implied, or assumes any legal liability or responsibility for the accuracy, completeness, or usefulness of any information, apparatus, product, or process disclosed, or represents that its use would not infringe privately owned rights. Reference herein to any specific commercial product, process, or service by trade name, trademark, manufacturer, or otherwise does not necessarily constitute or imply its endorsement, recommendation, or favoring by the United States Government or any agency thereof. The views and opinions of authors expressed herein do not necessarily state or reflect those of the United States Government or any agency thereof. 


\section{DISCLAIMER}

Portions of this document may be illegible in electronic image products. Images are produced from the best available original document. 
As-Rolled Uranium . . . . . . . . . . . . . . . . 8

Surface-Ground Uranium . . . . . . . . . . . . . 8

Aluminum . . . . . . . . . . . . . . . . 9

BOND TESTING • • . . . . . . . . . . . . . . . . 9

BONDING EXPERIMENTS . . . . . . . . . . . . . 10

Al-Si Dip Coats . . . . . . . . . . . . . . 12

Chromium Electroplates . . . . . . . . . . . 14

Nickel Electroplates . . . . . . . . . . . . . 14

Copper Electroplates. . . . . . . . . . . . . 16

Zinc Electroplate .. . . . . . . . . . . . 16

Nickel-Copper Electroplate . . . . . . . . . . . . 16

ROLLING CHARACTERISTICS . . . . . . . . . . . . . . 16

SELECTION OF AN INTERFACE METAL . . . . . . . . . . 18

ELECTROPLATING . • . . . . . . • . . . . . . . . 19

HEAT TREATMENT . . . . . . . . . . . . . . . 20

PROTOTYPE FUEL ELEMENT . . . . . . . . . . . . . . . . 24

CONCLUSIONS • . . . . . . . . . . . . . . . . . . . 28

REFERENCES • . • . . . . . . . . . . . . . . 29 


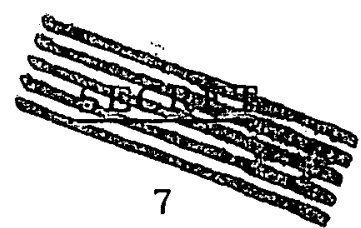

\title{
THE ROLL CLADDING OF URANIUM WITH ALUMINUM
}

\author{
H. A. Saller, S. J. Paprocki, and J. F, Delaney
}

The possibility of producing flat-plate aluminum-clad uranium fuel elements by rolling was investigated. The aluminum-to-uranium bond was found to be weak because of the formation of intermetallic compounds and the oxidation of the core during the preheat. Several interface coats on the uranium (chromium, copper, nickel, and zinc electroplates, as well as an Al-Si* dip coat) were tried. Nickel and copper gave the best bonds; the other materials gave relatively weak bonds. Nickel was selected for concentrated development on the basis of its apparent superior corrosion resistance when in contact with uranium. Factors affecting the quality of the nickel electroplate were investigated, and the anodic treatment was found to be critical. Heat treatment also has considerable effect on the bond; the bonds weaken after 5 min at 900 to $1100 \mathrm{~F}$. An extruded aluminum sheath will be used for cladding the fuel plates, and aluminum end plugs will be inserted in each end. The best bonds were obtained with copper-plated end plugs hot pressed to the ends of the plates. Edge bonding was obtained by rolling through grooved rolls. It was concluded that roll cladding can be used as a method of producing the aluminum-clad fuel plates.

\section{INTRODUCTION}

Several methods of producing flat-plate aluminum-clad uranium fuel elements are under investigation at Battelle. These methods are hot press bonding, extrusion cladding, solder bonding, and roll cladding. The present report deals with the results of the rolling experiments.

The fuel element under investigation embodies a normal uranium core 3.1 in. by 0.180 in. by several feet long, clad with approximately 0.02 in. of $2 \mathrm{~S}$ aluminum. An intermediate layer between the cladding and the core is not desired, but will be acceptable if necessary.

It is anticipated that a heat treatment will be required in order to improve the dimensional stability of the uranium. Two treatments are under consideration: beta quenching and controlled rolling in the high alpha

- $\mathrm{Al}-\mathrm{Si}$, refers to an aluminum-silicon alloy of approximately eutectic (12.5 w/o silicon) composition 58

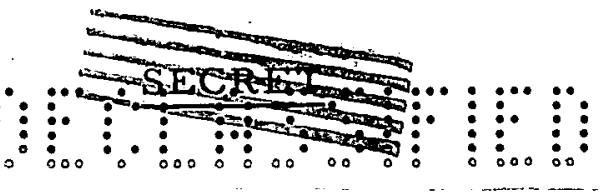




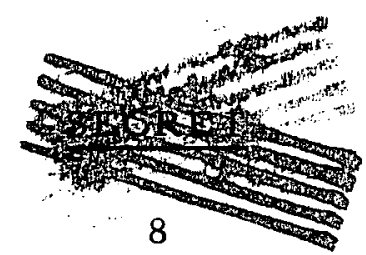

range. The cladding procedure depends upon which of these treatments is used. If a beta-quench treatment is used, cladding must follow the heat treatment because the aluminum is molten at the beta temperature.

Cladding after heat treatment must be accomplished with a minimum of deformation because any deformation of the core after the treatment may alter the structure of the uranium sufficiently to mask the beneficial effects of the treatment. However, cladding may be done as a part of the alpharolling stability treatment, and deformation will not be harmful. Because the alpha-rolling temperature necessary to stabilize uranium will exceed the copper-uranium-eutectic melting point, a copper interface layer would be undesirable.

Since the heat treatment has not been selected, a cladding procedure must be developed for both treatments. Before this can be accomplished, it is necessary to determine if an intermediate layer between aluminum and uranium is needed, and, if so, to select the most promising one for concentrated development.

\section{EQUIPMENT AND MATERIAL}

All rolling was done at a constant speed of $40 \mathrm{fpm}$ on a two-high mill equipped with 5 by 8 -in. rolls. Houghton Rust Veto No. 200 was used for lubrication. A resistance-heated muffle with a controlled helium atmosphere was used to heat the specimens for hot rolling.

\section{As-Rolled Uranium}

It would be an economic advantage if no surface machining of the core were required. Besides the actual cost of the machining, there is the additional cost of chip recovery. For this reason, an attempt was made to utilize uranium plate in the as-rolled condition. Uranium plate rolled by Superior Tube Company was supplied for use on all of the cladding projects. The use of such standard plate resulted in better correlation between the various cladding methods under investigation. The only surface treatment used was that necessary for electroplating or cleaning.

Surface-Ground Uranium

A considerable amount of work was done before Superior rolled plate Ђ̧G

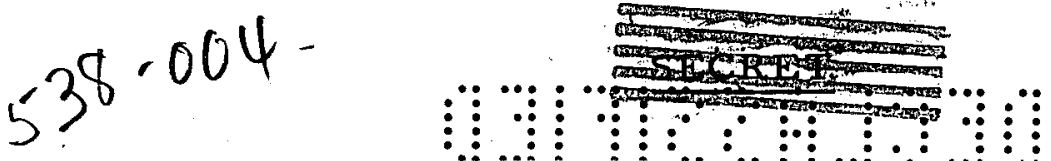


or center cuts from biscuits, to plate at $1050 \mathrm{~F}$ were used for this work. Generally, this plate was flattened by cold finishing about 5 per cent. About $1 / 32$ in. was removed during grinding.

\section{Aluminum}

Commercial sheets of $2 S$ aluminum were used in making the rolling packs. Before assembly, the aluminum was given the following cleaning treatment:

(1) Pickle 2 to $3 \mathrm{~min}$ in hot 15 per cent caustic soda

(2) Water rinse

(3) Pickle 1 to 2 min in 50 per cent nitric acid

(4) Water rinse and dry.

Other pickling treatments were tried, but they had no apparent effect on the bonding results $(1)^{*}$. This pickle is effective in removing foreign matter and roughening the surface of the aluminum.

\section{BOND TESTING}

A survey was made of possible quantitative bond-strength tests. However, none were found that would be accurate enough to warrant their use. An attempt was made to machine various test specimens from bonded plate. The stresses involved in these operations were generally great enough to rupture the bond in places. These unbonded areas made the tests very inaccurate. Other tests, such as brazing tensile bars to the surface, were not felt to be representative. The same criticism applies to tests that require packs rolled with dimensions which differ radically from those of the desired fuel plate. For instance, rolling with $0.25-i n$. cover plates would not duplicate the results with $0.020-$ in. cover plates.

Bond testing was done by the peel test. Although this method does not give quantitative results, the bonds could be compared with some accuracy. The test was generally performed by seizing the corner of the clad with pliers, and peeling it back if possible. One person did all of the testing so that he could compare the strengths of the bonds. The peel test is affected by the thickness of the cladding. The thicker the cladding, the

- References at end of report. 
easier it is to peel. This effect was taken into consideration by the tester as much as possible.

Tensile specimens were hot pressed in conjunction with the pressurebonding project. By comparing roll-clad plates with these specimens, it was possible to obtain approximate bond-strength values. The following system of nomenclature, based on this comparison, will be used throughout the present report.

\begin{tabular}{cllc} 
Bond & \multicolumn{1}{c}{ Peel Test } & & Tensile Strength \\
Excellent & The clad could not be peeled & 8,000 to $12,000 \mathrm{psi}$ \\
Good & The clad could be peeled only with difficulty & 6,000 to $8,000 \mathrm{psi}$ \\
Fair & The clad could be peeled fairly easily & No value \\
Poor & There was only weak contact & No value \\
None & There was no contact & .-
\end{tabular}

Although it was possible to compare the bonds more accurately than these five classifications indicate, only five degrees of strength were recorded. Thus, one "good" bond may be better than another "good" bond.

Metallographic examination was also used for bond evaluation. It was found to be impossible to correlate microstructure with the above strength classifications. The chief use of metallography was to determine the continuity of the bond and the extent of diffusion.

\section{BONDING EXPERIMENTS}

A picture-frame type of pack was used for the first bonding experiments. This pack was discarded because the core was oxidized when the cover plates were welded to the frame. A modified frame, shown in Figure 1 , was designed to prevent oxidation. The cover plates were welded to the three sides of the U-shaped frame. When this assembly was cool, the fore and plug were inserted. The pack was then clamped between waterOcooled blocks and welded shut.

The initial tests were run to determine the possibility of bonding uranium to aluminum with no interface layer between them. Since a brittle intermetallic is formed between aluminum and uranium, it was doubtful that a good bond could be formed. Uranium cores, 1 by 1 by 0.100 in., were pickled in 50 per cent nitric acid. These cores were sealed in packs

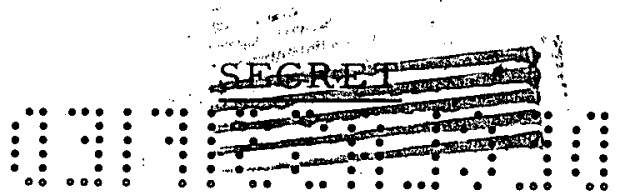



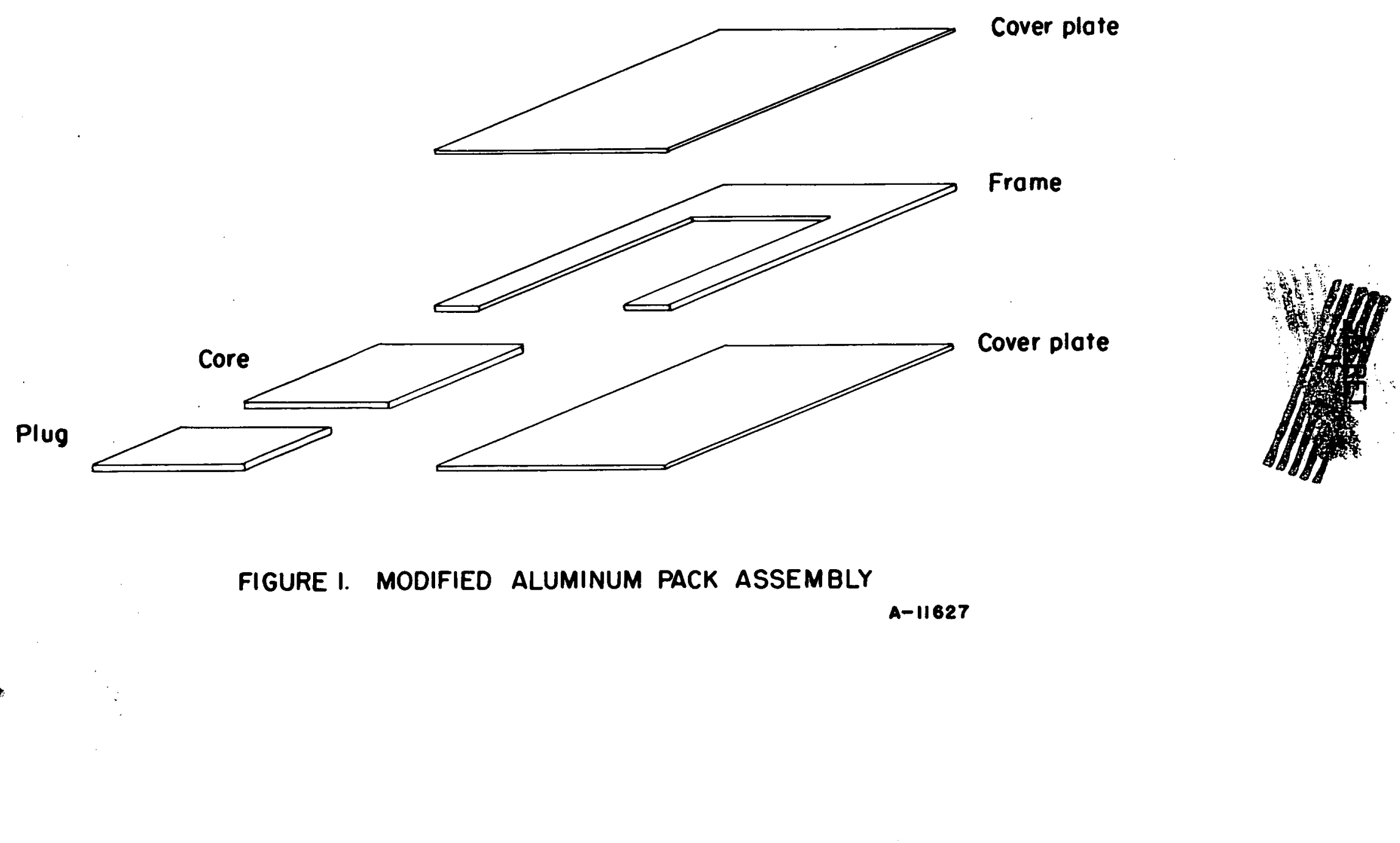

$\because \ldots$

: $\cdots: \cdots$

$\because \ldots$ llfeF

$\because \cdots+1$

$\cdots:$ \$

$\because \because$

$\cdots$

(2.....

$\because \cdots$

$\because \ldots$

FIGURE I. MODIFIED ALUMINUM PACK ASSEMBLY 


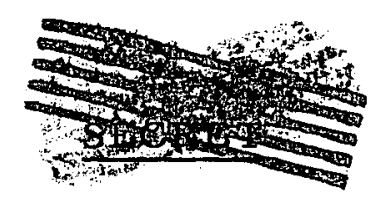

12

with 0.050-in. cover plates. Rolling temperatures of 600 to $1100 \mathrm{~F}$, and total reductions of 10 to 70 per cent, were used. A reduction per pass of 10 to 25 per cent was given, depending on the total reduction desired.

Only fair bonds could be obtained, and these only at high temperature and high reduction. Even then, the bonding was inconsistent; fair bonds could be obtained only two out of three times. This inconsistency in bonding results principally from oxidation of the core during the preheat. Most of the cores examined after rolling had black oxide films. At times, the layer was thick enough to prevent diffusion and thereby hinder bonding. Oxidation could be eliminated by evacuating the packs, but this procedure is not economically feasible in large-scale production.

Since the aluminum-to-uranium bond showed so little promise, it was abandoned. Work was concentrated on coatings that would prevent oxidation of uranium and would serve as diffusion barriers between aluminum and uranium. The chief guide in selecting metals for study as diffusion interfaces was work done in the pressure-bonding program. "Half dollar" sandwiches were hot pressed in a vacuum, with various intermediate metals between the clad and core. In this work, foils could be used as interfaces, since oxidation of the core would not interfere. Indium, iron, lead, molybdenum, tin, and zinc foils were used. Chromium, copper, and nickel were tried in the form of electroplates on the core. One dip alloy, aluminum-12.5 w/o silicon (Al-Si), was tried because considerable experience has been developed with this alloy in cladding other fuel elements.

On the basis of these tests, chromium, copper, nickel, zinc, and the Al-Si dip were selected for roll-bonding studies. These interfaces showed the most promise in the pressure-bonding studies, and they had acceptable nuclear properties. Of added importance to roll-cladding studies is the fact that these metals could be applied as protective coatings to the uranium surface. The Al-Si was applied by dipping, the others by electroplating.

A series of packs was rolled with these intermediate metals. Results of the roll-bonding tests appear in Figure 2. Detailed results with each of the barriers are given in the sections that follow. Surface-ground cores, 1 by 1 by 0.100 in., were used in packs with $0.050-$ in. cover plates. A standard electroplate thickness of 0.0005 in. was used. The Al-Si dip coat varied from 0.003 to 0.005 in. in thickness.

\section{Al-Si Dip Coats}

Aluminum-12. $5 \mathrm{w} / \mathrm{o}$ silicon alloy was used for the dip coat. The fact that this alloy is molten at $1070 \mathrm{~F}$ limits the rolling temperature. Good bonds were obtained at high reductions, but these bonds were not uniform.

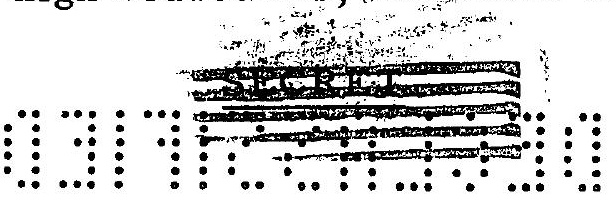




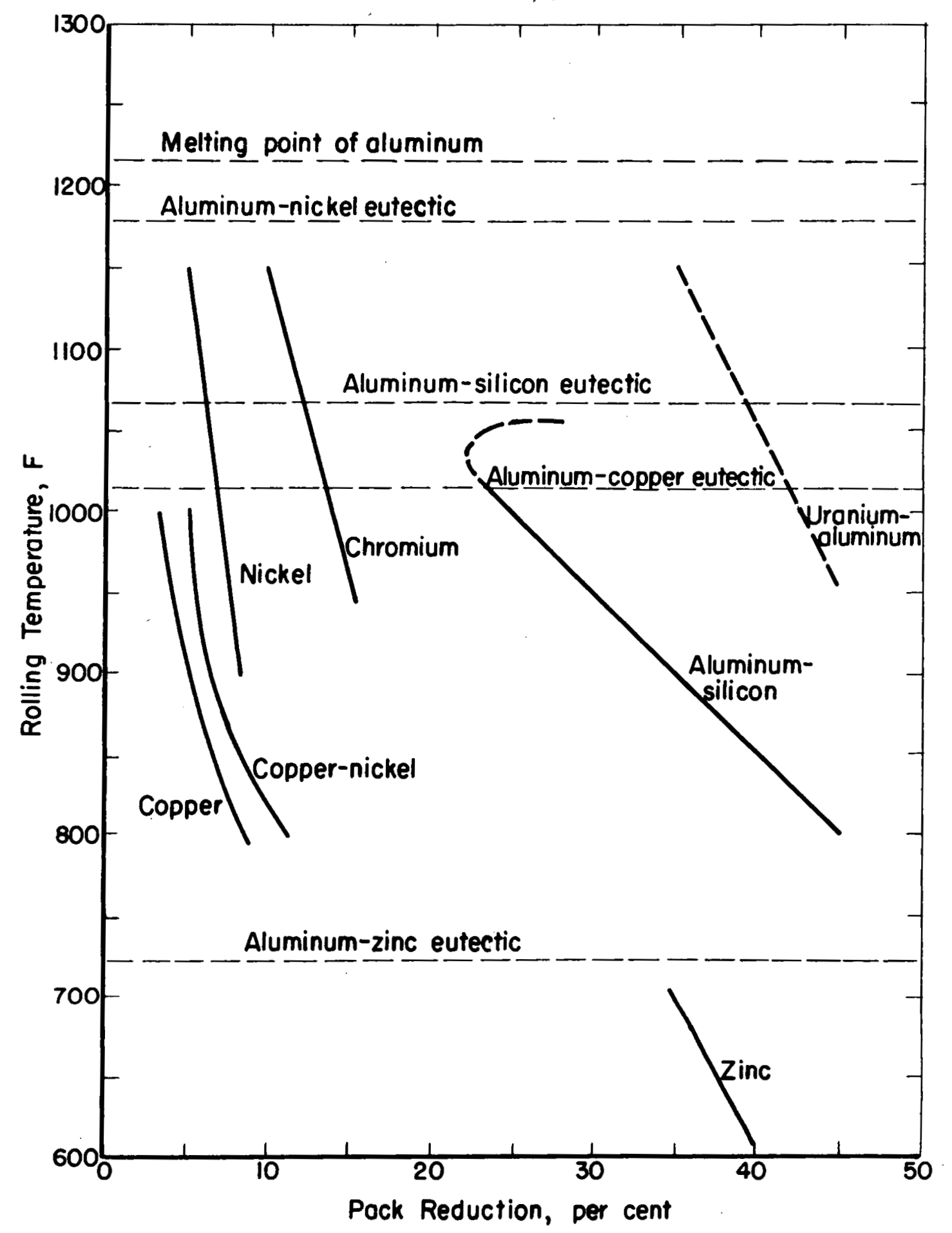

FIGURE 2. TEMPERATURE AND REDUCTION NECESSARY FOR GOOD BONDING WITH VARIOUS INTERFACE METALS Conditions to the right of individual lines designating interface metals are required for good bonding A-11628

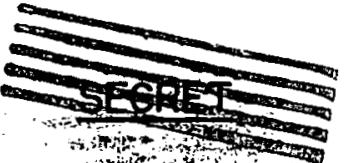




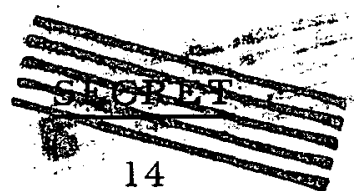

Most of the bonds tested had one or more weak spots. The uranium core was generally oxidized at these spots, indicating that the Al-Si offered poor protection in some areas. The cross section of a typical bond line is shown in Figure 3. There is a thick layer of intermetallic compound formed between the alloy and the uranium. This formation limits the maximum strength possible with this barrier to a relatively low value. None of the bonds formed could be classified as excellent.

As the rolling temperature increased, less reduction was required to obtain good bonds. However, near the eutectic temperature, a point was reached where the formation of the intermetallic was so rapid that good bonds could not be formed. This fact rules out "roll brazing" and the possibility of giving light reductions above the eutectic temperature. The high reductions necessary for bonding are prohibitive because of the "end effect" discussed later in this report.

\section{Chromium Electroplates}

Good bonds were obtained at reductions around 15 per cent when chromium electroplates were used. This reduction is too large to be tolerated in a beta-quenched core, however. The bond is similar to that formed with Al-Si. A brittle intermetallic zone, formed between the chromium and the aluminum, is shown in Figure 4. This zone does not seem to grow as rapidly as does the Al-Si - uranium intermetallic, and it can be rolled at high temperatures with success. The bond is stronger and more uniform than the Al-Si bond; but none of the bonds can be classified as excellent.

$\underline{\text { Nickel Electroplates }}$

Very small pack reductions, on the order of 5 per cent, are required to obtain good and excellent bonds with nickel electroplate. The bonds are uniform and possess some ductility. Figure 5 shows the cross section of a typical bond line. Several diffusion zones are present, but none have the brittle appearance of the Al-Si - uranium zone. The rolling temperature is limited somewhat by the presence of the aluminum-nickel eutectic at $1184 \mathrm{~F}$.

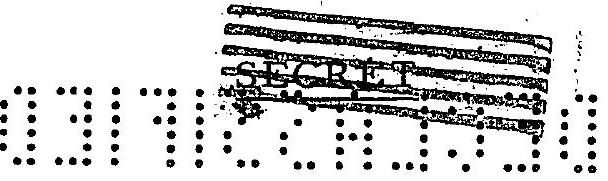



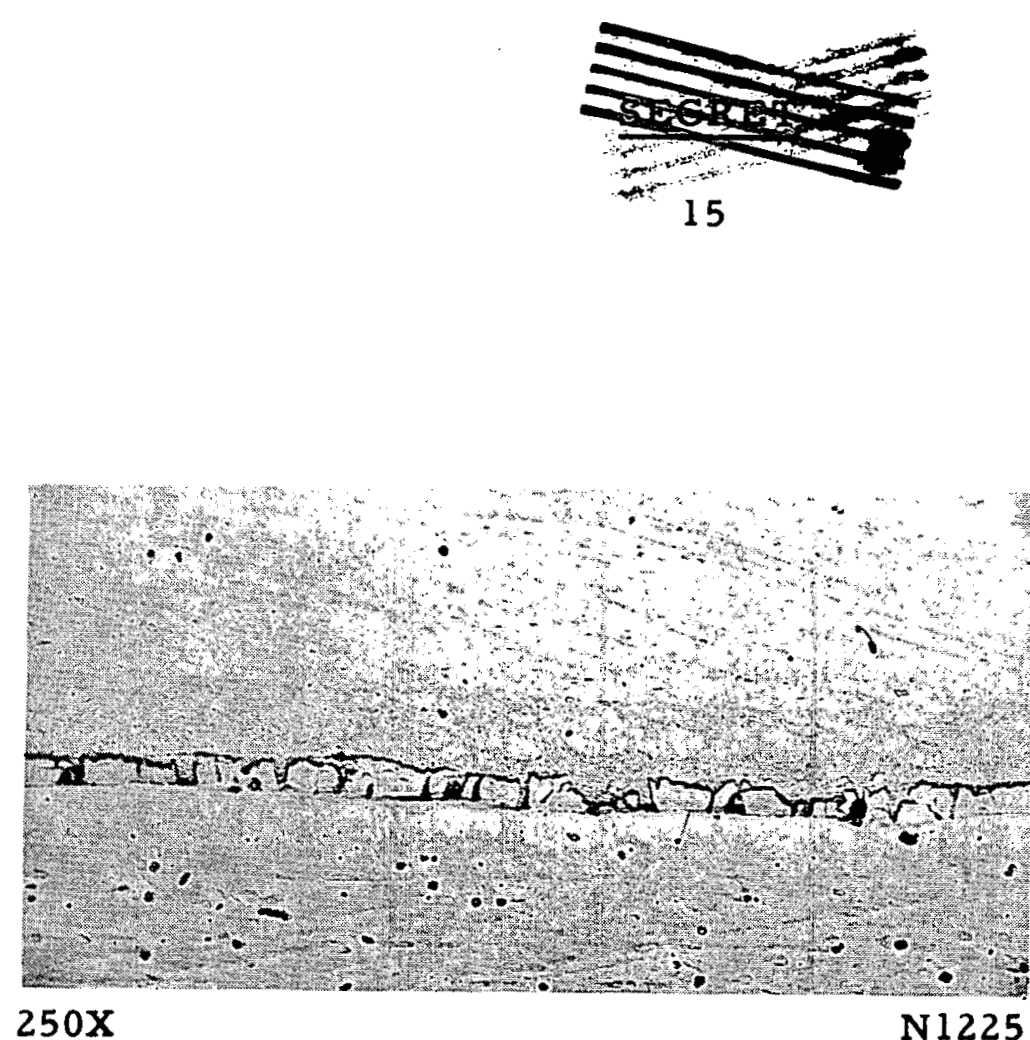

\author{
Aluminum \\ Aluminum-silic on \\ Uranium
}

$250 X$

N1225

FIGURE 3. ALUMINUM-URANIUM BOND WITH Al-Si INTERFACE

Rolling Temperature, $1100 \mathrm{~F}, 0.003-\mathrm{In}$. Al-Si, 32 Per Cent Reduction

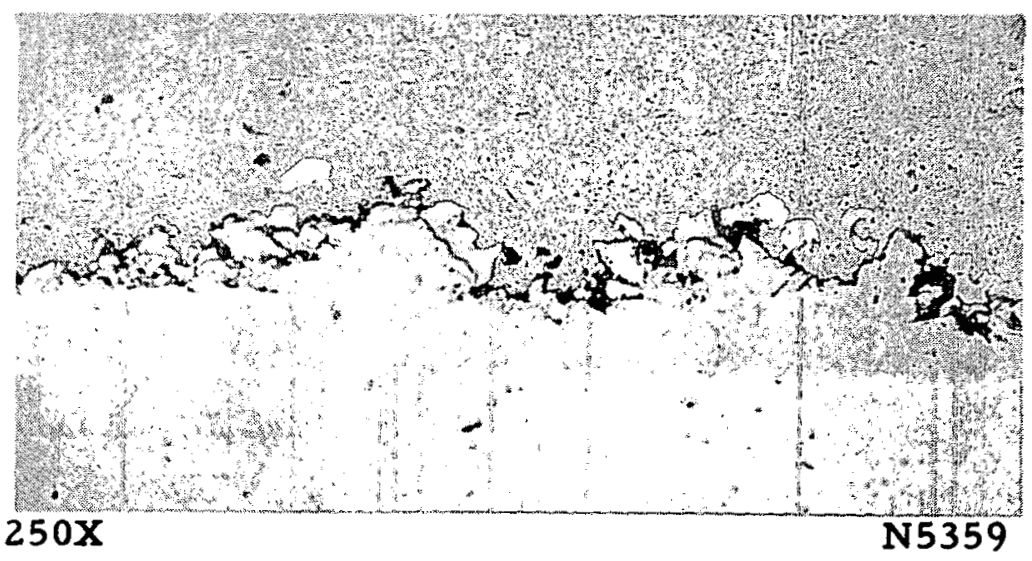

\author{
Aluminum \\ Uranium
}

FIGURE 4. ALUMINUM-URANIUM BOND WITH CHROMIUM INTERFACE

Rolling Temperature, 1150 F, 0.005-In. Chromium, 20 Per Cent Reduction

5 


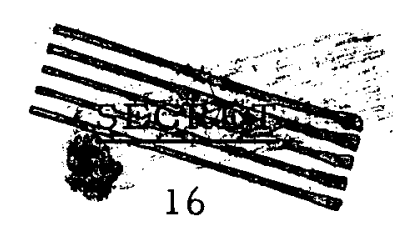

Copper Electroplates

The results with copper are similar to those with nickel, but slightly smaller reductions are needed to form good bonds, and the bonds are somewhat stronger. A cross section of a typical bond line is shown in Figure 6. The rolling temperature is limited by the copper-aluminum eutectic at $1018 \mathrm{~F}$. This temperature is too low for the alpha-rolling stability treatment, but, since very little reduction is required, this factor is probably not important.

\section{$\underline{\text { Zinc Electroplate }}$}

The rolling temperature for zinc-plated uranium is limited by the eutectic between zinc and aluminum at $719 \mathrm{~F}$. High reductions are necessary to obtain good bonds. The bonds are uniform and fairly ductile, but are not as strong as the Al-Si bonds. The zinc was studied on the assumption that a low rolling temperature might be desirable because of the rolling characteristics of the packs. The reductions required for bonding are too high for this metal to be used, however.

\section{Nickel-Copper Electroplate}

The combination of electroplated nickel and copper was tried. A 0.0005-in. nickel electroplate was deposited on the core, and this was followed by a flash copper plate. The properties of the combined plate are about the average of the properties of the individual plates. The bond is slightly stronger than the nickel-plate bond, but is weaker than the copper-plate bond.

\section{ROLLING CHARACTERISTICS}

As would be expected, the soft aluminum was reduced more than the uranium during rolling. A large void was formed between the core and the trailing end of the frame as a result of this difference in elongation. Because of the apparent magnitude of this effect, a test was made to determine if the pack could be reduced without deforming the core. This ability to reduce without core deformation would be an asset in solving the reduction problem with the beta-quenrhed core.

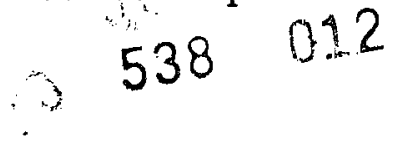



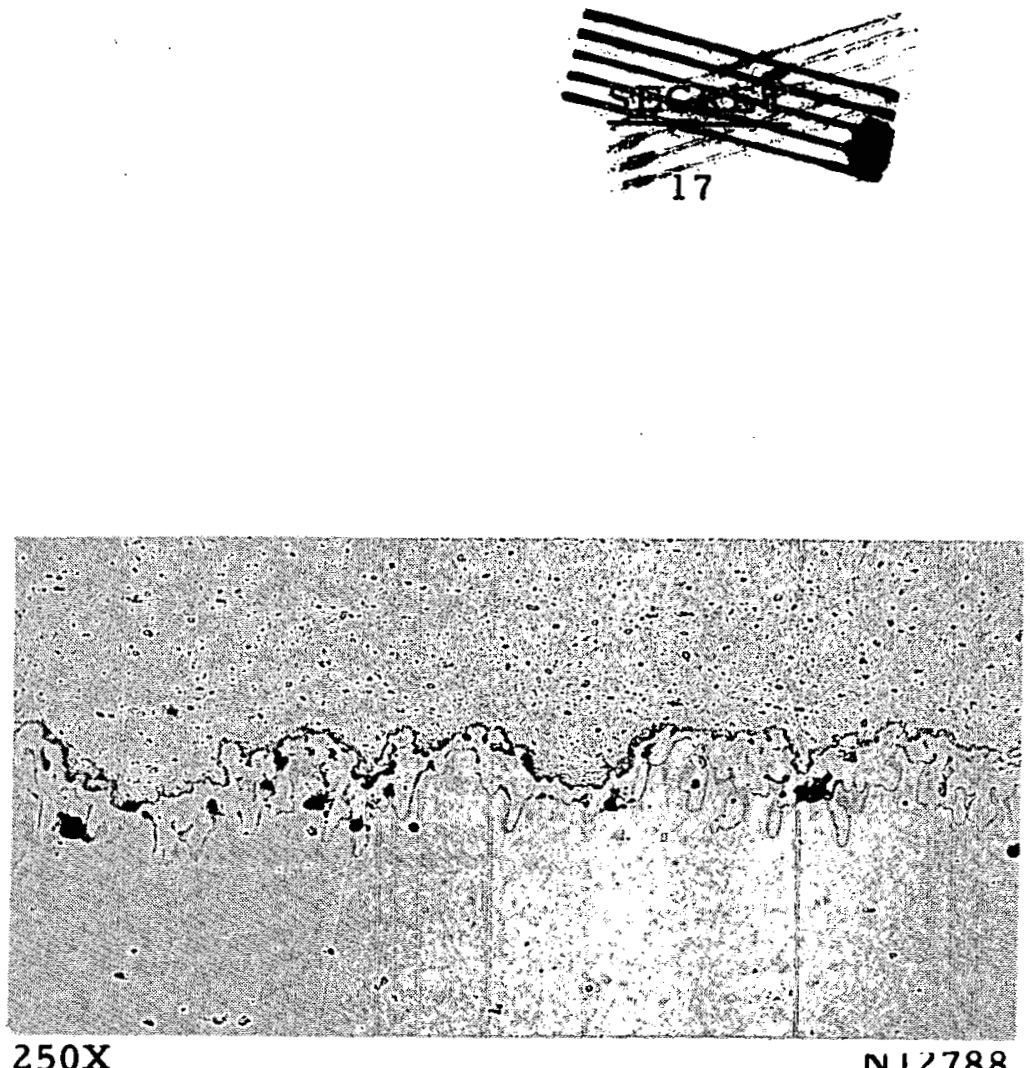

Aluminum

Uranium

N 12788

FIGURE 5. ALUMINUM-URANIUM BOND WITH NICKEL INTERFACE

Rolling Temperature, 1100 F, 0.0005-In. Nickel, 5 Per Cent Reduction

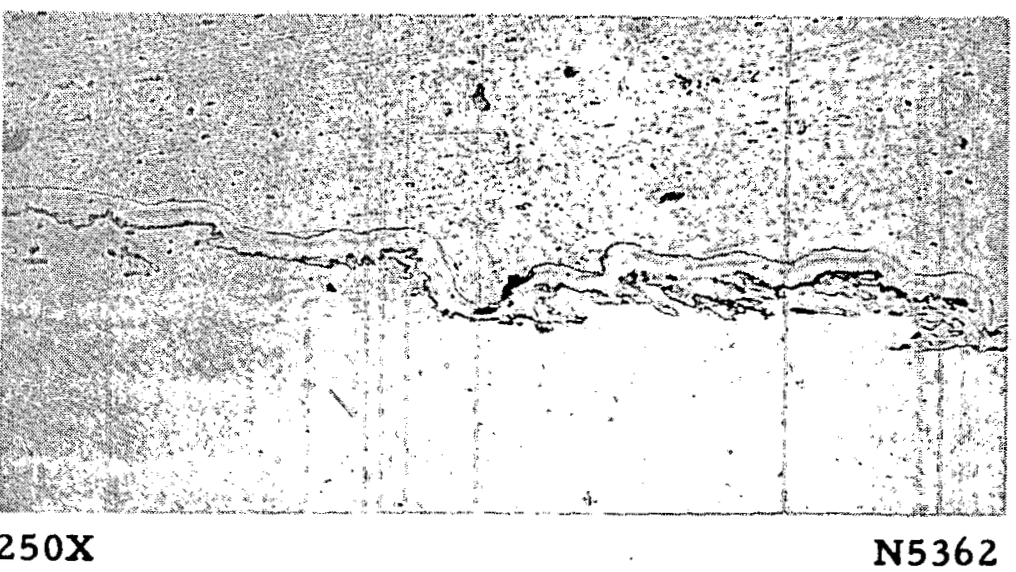

Aluminum

Uranium

FIGURE 6. ALUMINUM-URANIUM BOND WITH COPPER INTERFACE

Rolling Temperature, 950 F, 0.0005-In. Copper, 8 Per Cent Reduction

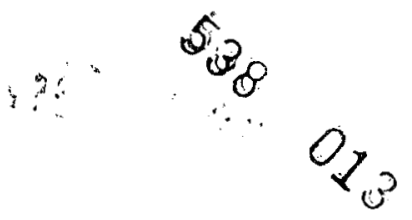


The first packs rolled had cores 1 by 1 by 0.10 in. and a cover 0.05 in. thick. With light reductions of 3 to 4 per cent per pass, the pack could be reduced 14 per cent before core deformation occurred. With reductions per pass of 10 per cent or more, the limit was lowered to 10 per cent. Once the core did reduce, it reduced at the same rate as the pack. This relation was found to be independent of rolling temperature between 800 and $1150 \mathrm{~F}$ and independent of the presence or absence of bonding between the cladding and the core. The relation depends to some extent on the relative thickness of the core and the cladding.

Unfortunately, the maximum reduction without deformation drops to approximately 2 per cent when cores greater than 2 by 3 in. are used. Below $800 \mathrm{~F}$, maximum reduction without deformation increases, reaching a maximum of 3 per cent at room temperature.

The probable explanation for this effect of critical size is what is called the end effect. Whenever the core is reduced, there is a nonuniform deformation. The center of the core is reduced more than the ends or edges. This disproportionate reduction results in a concave core, and the effect becomes progressively worse with increased reduction. The main "hourglass" effect is along the length of the core; the effect across the width is minor. When high reductions are given, the large ends of the core puncture the cladding. The breakthrough generally occurs at about 40 per cent reduction.

When the 1 by $1-i n$. cores were used, they were short enough so that effectively they were all ends. These ends were not reduced disproportionately.

Core reduction, as the term is used hereafter in this report, refers to the reduction of the center of the plate. On large plates, this is the principal reduction, since the end-effect is limited to within about $1 / 2 \mathrm{in}$. of the core end.

\section{SELECTION OF AN INTERFACE METAL}

All of the interface metals that were investigated offered some possibilities. However, since a production method was desired as soon as possible, the most promising interface was selected for concentrated development. On the basis of bonding studies, the nickel and the copper possessed the best properties; excellent bonds could be obtained with a minimum of reduction, and the bonds were continuous and possessed some ductility.<smiles>[SeH]=[SbH]</smiles><smiles>O[GeH2]</smiles>

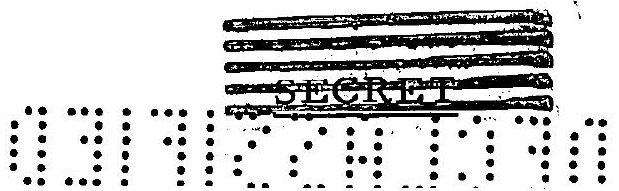




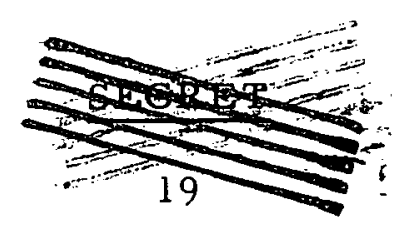

The nickel barrier was selected over the copper on the basis of the corrosion properties of the bond. When exposed to boiling water, all of the uranium coatings ultimately failed by a mechanism of undercutting. Preliminary tests indicated, however, that the incubation period for the attack varies considerably for each of the metals. The nickel and Al-Si interface metals remain relatively sound after $24 \mathrm{hr}$ of exposure to boiling water. Several of the specimens with a copper interface were undercut with $12 \mathrm{hr}$ of exposure. It is anticipated that the longer incubation period of the nickel may be advantageous if a break develops. Under such a circumstance, detection of the break and removal of the element from the reactor may be possible before complete failure occurs.

The nickel-copper plate, mentioned earlier, was used in an attempt to combine the corrosion resistance of nickel with the superior bonding characteristics of copper. Bonding was improved slightly, and the resulting corrosion resistance was comparable to that of the nickel interface. However, the improvement does not appear to be sufficient to justify the additional plating step.

The following tabulation summarizes the properties on which the selection of the nickel interface was based.

\begin{tabular}{lcccc}
\multicolumn{1}{c}{ Interface } & Bond Strength & $\begin{array}{c}\text { Reduction For } \\
\text { Good Bonding, per cent }\end{array}$ & Corrosion Resistance \\
\cline { 1 - 1 } Al-Si & Low & & 25 at $1100 \mathrm{~F}$ & Good \\
Chromium & Fair & 12 at $1100 \mathrm{~F}$ & -- \\
Nickel & High & 5 at $1100 \mathrm{~F}$ & Good \\
Copper & High & 3 at $975 \mathrm{~F}$ & Fair \\
Nickel-Copper & High & 4 at $975 \mathrm{~F}$ & Good
\end{tabular}

\section{ELECTROPLATING}

One of the principal factors affecting the bond with nickel is the quality of the electroplate. Therefore, the study of the plating process was intensified when nickel was selected for development. Initially, the re was considerable variation in the electroplate. Roll-cladding results with one batch of plates were difficult to duplicate with another batch. As the work progressed, the variables that caused the inconsistency were identified and studied. With improvements resulting from this study, it was possible to study roll-cladding variables without danger of the plate quality invalidating the results. This report will discuss the electroplating variables on $p_{\rho}$ iefly.

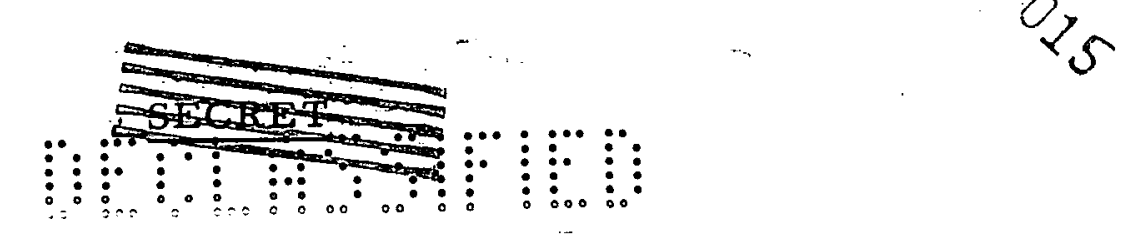




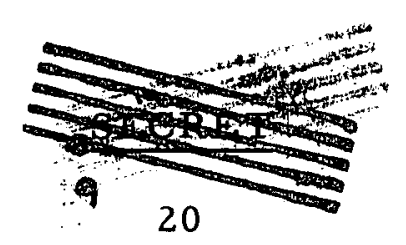

Initially, surface-ground uranium plate was used. This was later replaced with as-hot-rolled plate. These plates were grit blasted to remove scale and surface inclusions. The roughness that results from blasting appears to be an asset in bonding. After grit blasting, the plates were degreased with a solvent and rinsed with an alkaline bath and water. The plate was then pickled in 50 volume per cent nitric acid preparatory to anodic etching.

An attempt was made to eliminate the initial grit-blasting operation by using a more penetrating hot-pickling operation. The bonding results with this surface were not as good as the results with the grit-blasted surface. The electroplate was darker initially, and darkened still more with time. When the bond was examined metallographically, a thin black layer was found between the nickel plate and the uranium. Such layers did not occur when grit blasting was used.

The pickled plate was anodically etched in an aqueous solution containing 50 volume per cent phosphoric acid and 2 volume per cent hydrochloric acid. At first, a current density of approximately $50 \mathrm{amp} / \mathrm{sq} \mathrm{ft}$ was used. This current density is apparently on a critical borderline. Above this range, polarization of the uranium occurs and the etched surface is very smooth. Below this range, there is no polarization, and the surface is roughened considerably by the treatment. The electroplates on the rough surface result in better bonds than those on the smooth surface. Whether the roughness is a major factor in improving the bond or is only an indication of some other factor is not known. Recently a current density of $25 \mathrm{amp} / \mathrm{sq} \mathrm{ft}$ for $40 \mathrm{~min}$ has been used with very good, consistent results.

Another bonding variable studied was plating thickness. It is desirable that the electroplate be kept as thin as possible, since the thermal-neutronabsorption cross section for nickel is higher than that of aluminum. To determine the minimum thickness that could be used, packs were rolled with nickel interface layers $0.0002,0.0003$, and 0.0004 in. thick. The 0.0004-in. barrier gave about the same results as did the 0.0005-in. layer. The two thinner barriers were somewhat weaker.

\section{HEAT TREATMENT}

In all preliminary work, the plates were annealed $5 \mathrm{~min}$ at the rolling temperature after they had been reduced. This anneal was generally followed by an air cool. After the nickel electroplating process was developed, a series of tests was run to determine the effect of heat treating variables on the bond. Tests run before good quality electroplates had been developed were generally inconclusive.

538016 
The first experiments were run to determine the effect of annealing time and temperature. A 0.0005-in. nickel barrier was used in these tests to make correlation with previous work more accurate. A few packs with 0.0004-in. nickel barriers were run parallel to these tests, and no radical differences were found between the results with the two thicknesses. Rolling was done at 900 and $1100 \mathrm{~F}$, and the packs were annealed at the rolling temperature for periods up to $30 \mathrm{~min}$. The packs were air cooled after annealing.

The bond strength did not change after annealing for periods up to 5 min. However, when the packs were annealed for over $5 \mathrm{~min}$, the bond strength decreased until, at $30 \mathrm{~min}$, there was little or no bond strength remaining. This drop occurred at both of the rolling temperatures. Figures 7, 8, and 9 illustrate the progression of diffusion at the bond line, at 5,15 , and $30 \mathrm{~min}$, respectively. Several distinct diffusion zones are present, but identification of these has not been possible. All of the nickel appears to be alloyed to some extent soon after rolling. One indication of this alloying is that the corrosion resistance of nickel-plated uranium begins to drop after a $15-\mathrm{min}$ anneal at $1100 \mathrm{~F}$. Alloying of the nickel plate is probably the cause of this drop.

A similar series of packs was rolled, then water quenched after anneals up to $15 \mathrm{~min}$ at the rolling temperature. There was no significant difference in the bond strengths of packs with either of the cooling rates. There was also no visible difference in the microstructure of the bond line with either treatment.

No definite correlation has been found between bond strength and microstructure. Generally speaking, the thinner the diffusion zone, the better the bond. This has not been so in every case, especially when in weak bonds the contact between the surfaces has been so poor that diffusion could not occur to any extent. No critical size of the diffusion zone, at which the bond weakens or fails, has been found.

As mentioned in the section Rolling Characteristics, the difference in reduction between the pack and the core above $800 \mathrm{~F}$ is about 2 per cent. At lower temperatures, this difference increases slightly. To take advantage of this increase, some packs were rolled at room temperature and at $600 \mathrm{~F}$, and were then diffused at $800 \mathrm{~F}$. Poor bonds were formed, probably because of the lack of intimate contact at the low reductions. A similar series was rolled with an 8 per cent reduction. Good bonds were formed in this case. However, the higher reductions necessary for good contact probably outweigh the advantage of rolling at low temperature. A cross section of one of these plates is shown in Figure 10 .
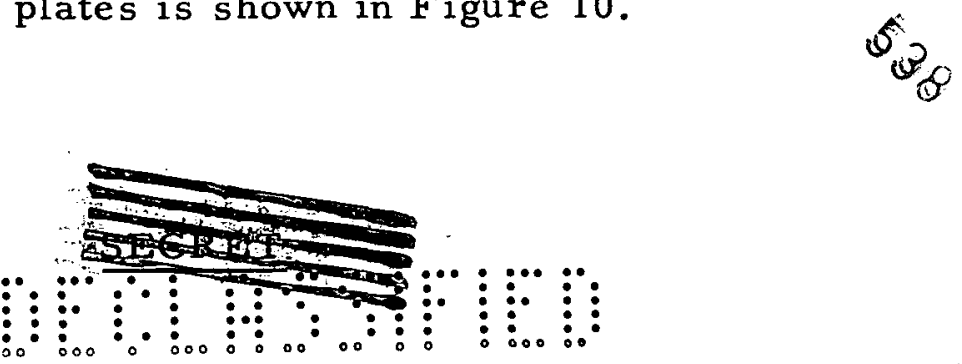


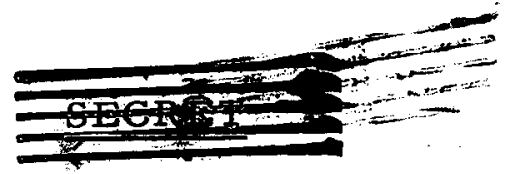

$22^{-}$

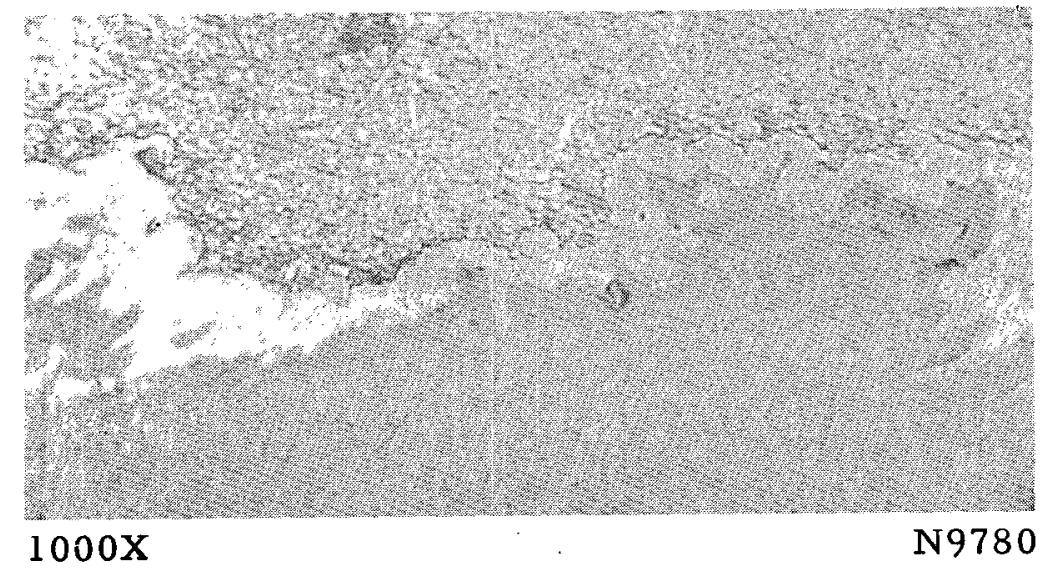

Aluminum

Uranium

FIGURE 7. ALUMINUM-URANIUM BOND WITH NICKEL INTERFACE

Rolled and Annealed $5 \mathrm{Min}$ at $1100 \mathrm{~F}, 0.0005-\mathrm{In}$. Nickel, 1. 6 Per Cent Reduction

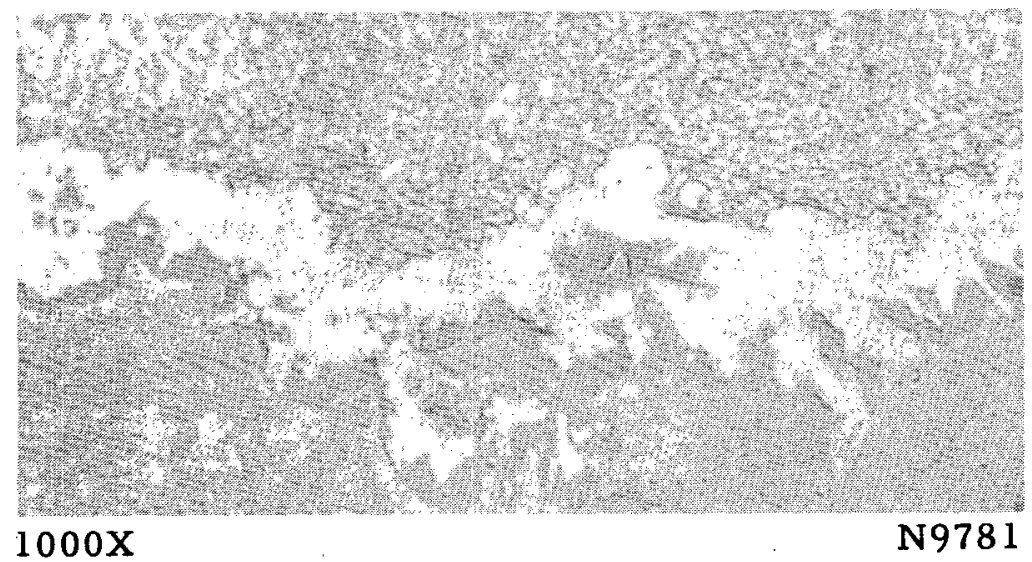

Aluminum

Uranium

FIGURE 8. ALUMINUM-URANIUM BOND WITH NICKEL INTERFACE

Rolled and Annealed $15 \mathrm{Min}$ at $1100 \mathrm{~F}, 0.0005-\mathrm{In}$. Nickel, 2 Per Cent Reduction
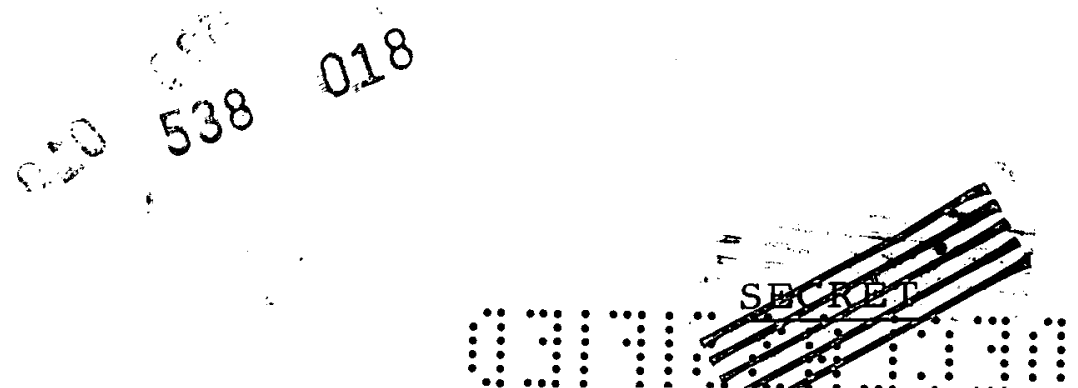


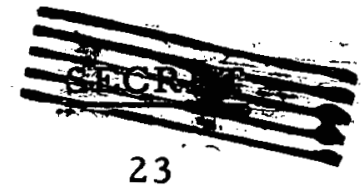

23

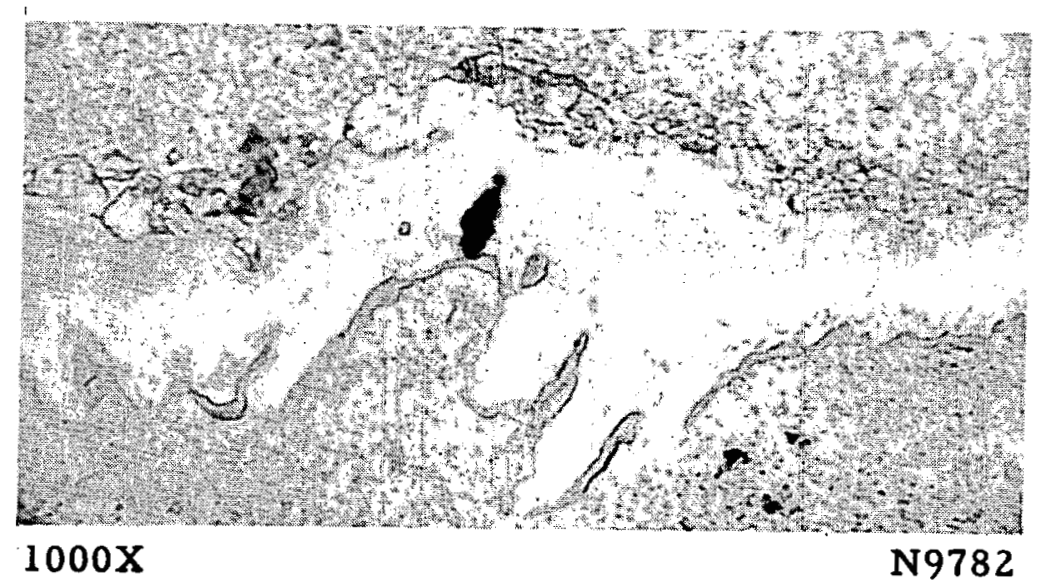

Aluminum

Uranium

FIGURE 9. ALUMINUM-URANIUM BOND WITH NICKEL INTERFACE

Rolled and Annealed $30 \mathrm{Min}$ at $1100 \mathrm{~F}, 0.0005-\mathrm{In}$. Nickel, 2. 7 Per Cent Reduction

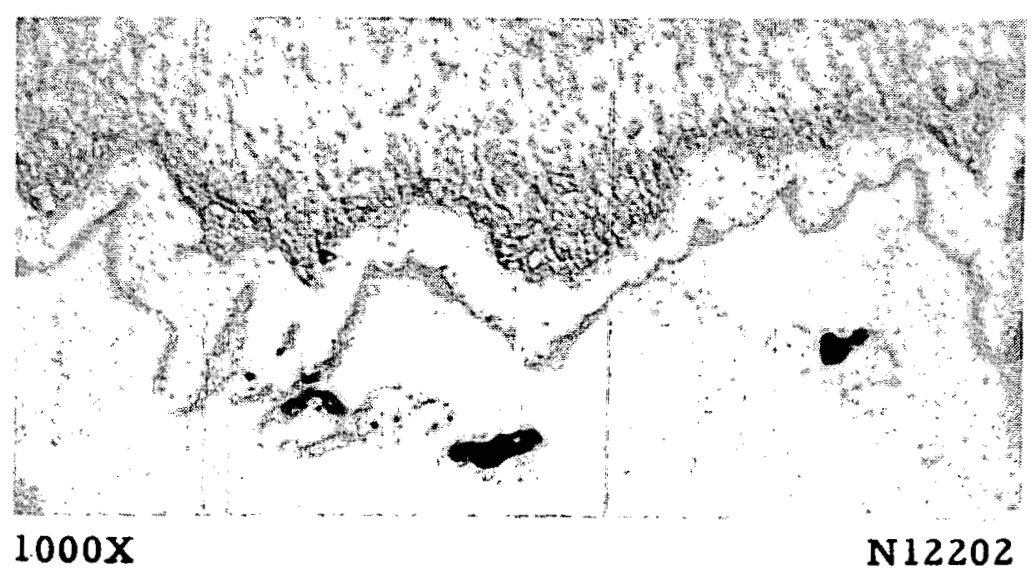

FIGURE 10. ALUMINUM-URANIUM BOND WITH NICKEL INTERFACE

Rolled at $600 \mathrm{~F}$ and Annealed $20 \mathrm{Min}$ at $800 \mathrm{~F}, 0.0005-\mathrm{In}$. Nickel, 8. 6 Per Cent Reduction

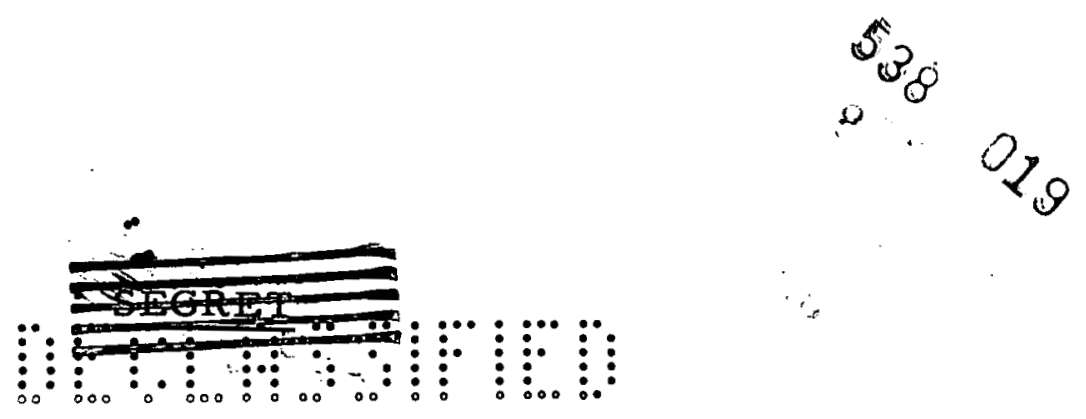


PROTOTYPE FUEL ELEMENT

One of the major objectives of this work was to develop a method of producing a prototype fuel element. Such an element would be clad on all surfaces with aluminum. It was assumed that a much more reliable fuel plate could be fabricated if a seamless aluminum sheath were used instead of a welded picture-frame type of assembly. An extruded sheath, of the design shown in Figure 11, was supplied to Battelle for this work. Aluminum end plugs sealed on both ends of the tube would produce a watertight element.

One method of attempting to obtain an intimate contact between the aluminum end plugs and the uranium core during rolling is to fasten the end plugs to the core by means of pins and lap joints. For this work, plates approximately 3.10 by 0.18 by $18 \mathrm{in.} \mathrm{were} \mathrm{used.} \mathrm{These} \mathrm{plates} \mathrm{were}$ fastened to the aluminum end plugs by means of five aluminum-alloy pins, Figure 12 .

A series of plates was rolled to determine the feasibility of bonding the end plugs to the sheath by rolling. Copper-plated and nickel-plated plugs were used. The rolling temperature with the copper-plated plugs was $900 \mathrm{~F}$; with the nickel-plated plugs, $1100 \mathrm{~F}$. Reductions of 4 to 5 per cent were given. The bonds formed with both types of plug were weak. There was evidence of diffusion in places, but, generally, there was only mechanical contact.

Several methods of improving end-plug bonding were tried. The end plug was made 0.015 in. thicker than the core. This increased size resulted in more pressure and reduction on the end for a given pack reduction. The bonds improved, but they were still classed as poor. The best results were obtained by hot pressing the leading end of the pack before rolling. This technique produces a good universal bond, which is further improved during rolling. Then the rolling pass bonds the body of the plate and the trailing end is bonded last by another hot-pressing operation. The ends were pressed at $600 \mathrm{psi}$ and $950 \mathrm{~F}$ for $5 \mathrm{~min}$. The cross sections of two of the pinned ends, pressure bonded and rolled, are shown in Figure 13. The dark line along the bond line is an etching effect, not a void. Highly magnified cross sections of the aluminum-to-aluminum bond with both nickel and copper interfaces are shown in Figures 14 and 15. The copper bond is strong and universal; the nickel bond is weaker and has some voids.

A clearance of 0.016 in. was allowed between the sheath and the core on all sides to facilitate the insertion of the core. This clearance prevented damage to the electroplate as the core was inserted. However, it resulted in a void along the edge of the core which had to be closed, since edge bonding is required. Edge pressure must be applied during rolling, as there is insufficient spregedduring the fabrication operation to close the edge void. 

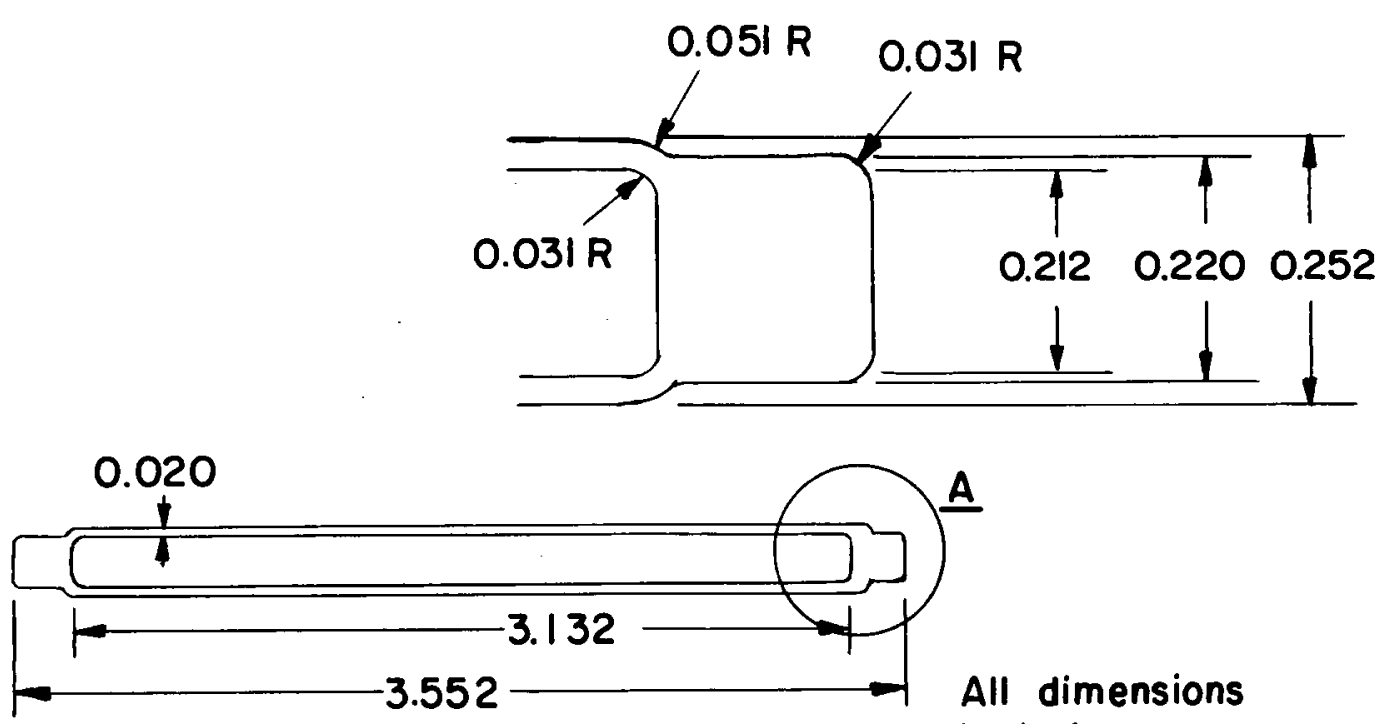

All dimensions

in inches

FIGURE II. EXTRUDED ALUMINUM SHEATH

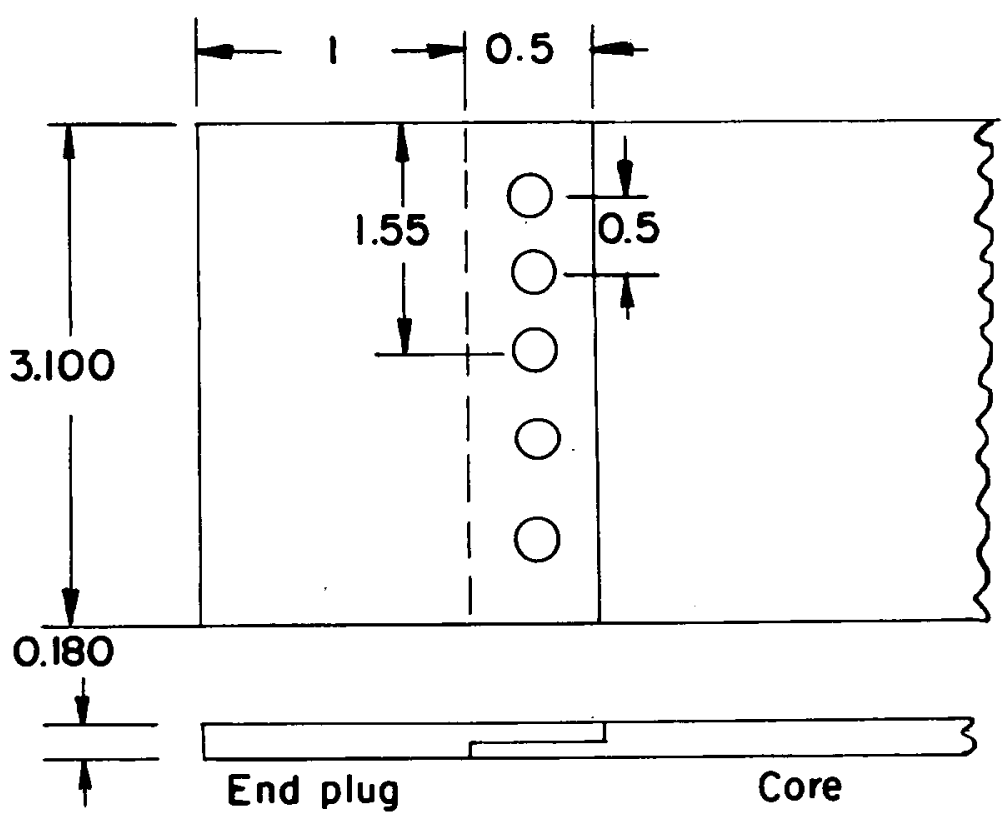

All dimensions in inches

FIGURE 12. LAP JOINT BETWEEN END PLUG AND CORE

50 
26

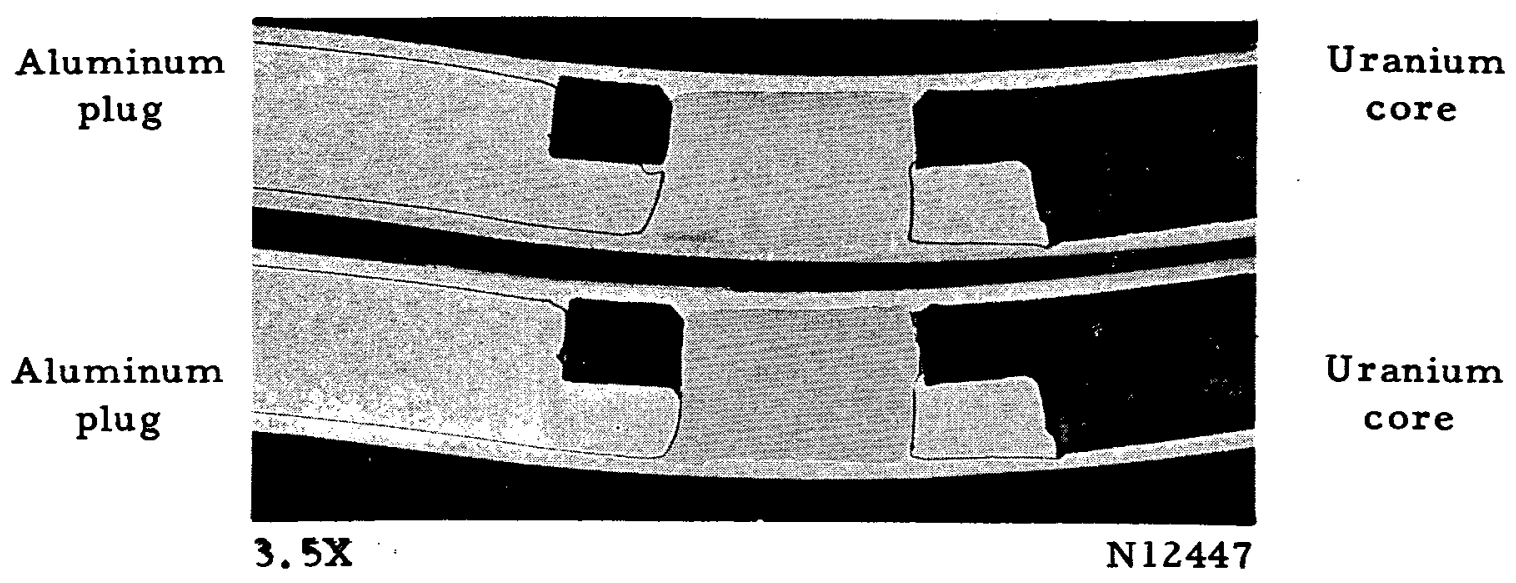

FIGURE 13. CROSS SECTION OF LAP JOINT AND PINS AFTER ROLLING

Rolling Temperature, $900 \mathrm{~F}, 0.0005-\mathrm{In}$. Nickel on Uranium Core, 0.0005-In. Copper on Aluminum Plug

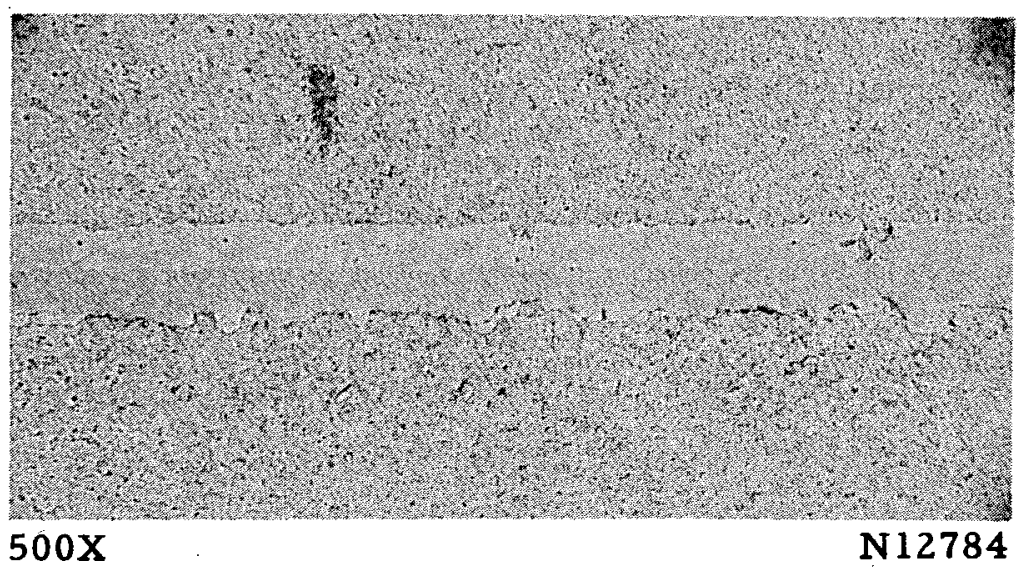

FIGURE 14. ALUMINUM-ALUMINUM BOND WITH COPPER INTERFACE Rolling Temperature, 900 F, 4 Per Cent Reduction

538. 022 

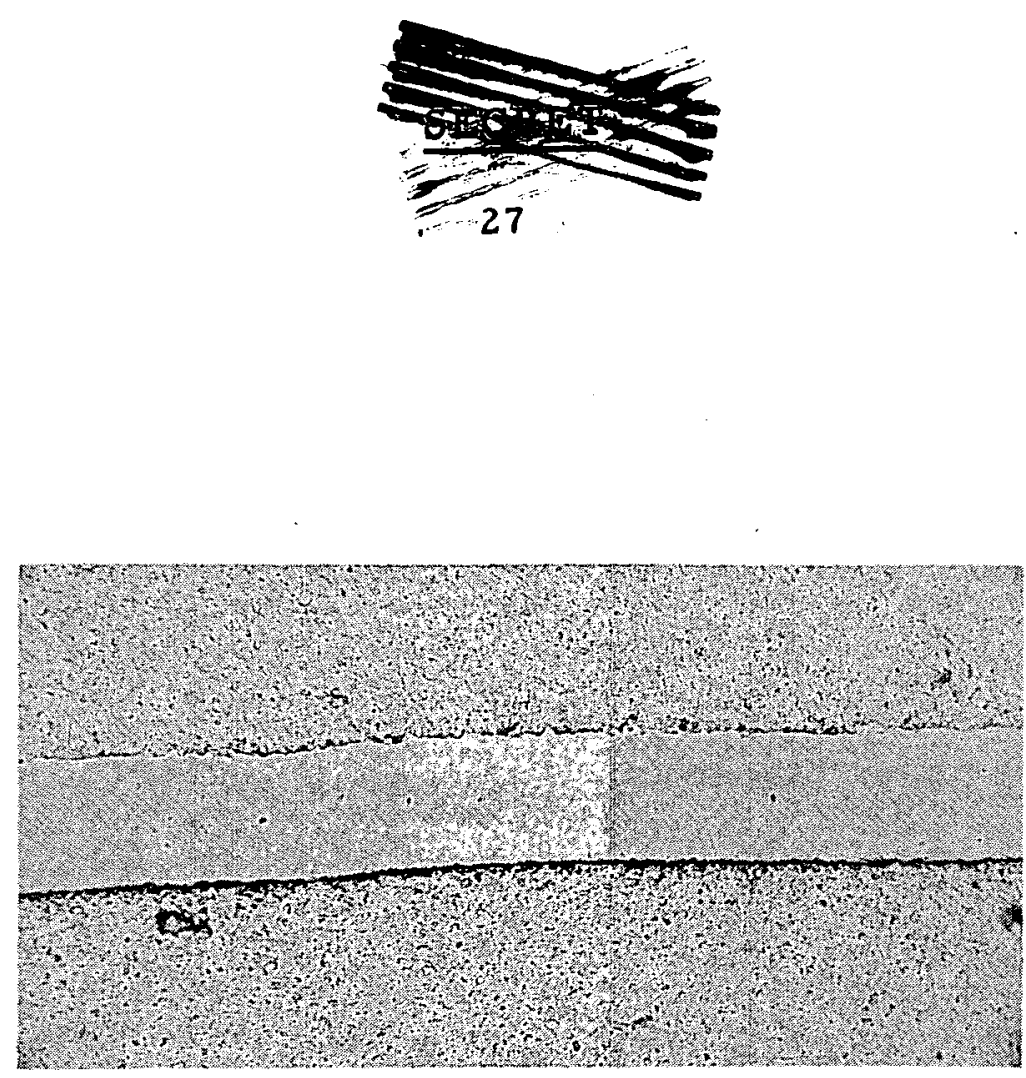

$500 \mathrm{X}$

N12785

FIGURE 15. ALUMINUM-ALUMINUM BOND WITH NICKEL INTERFACE Rolling Temperature, 1100 F, 4 Per Cent Reduction

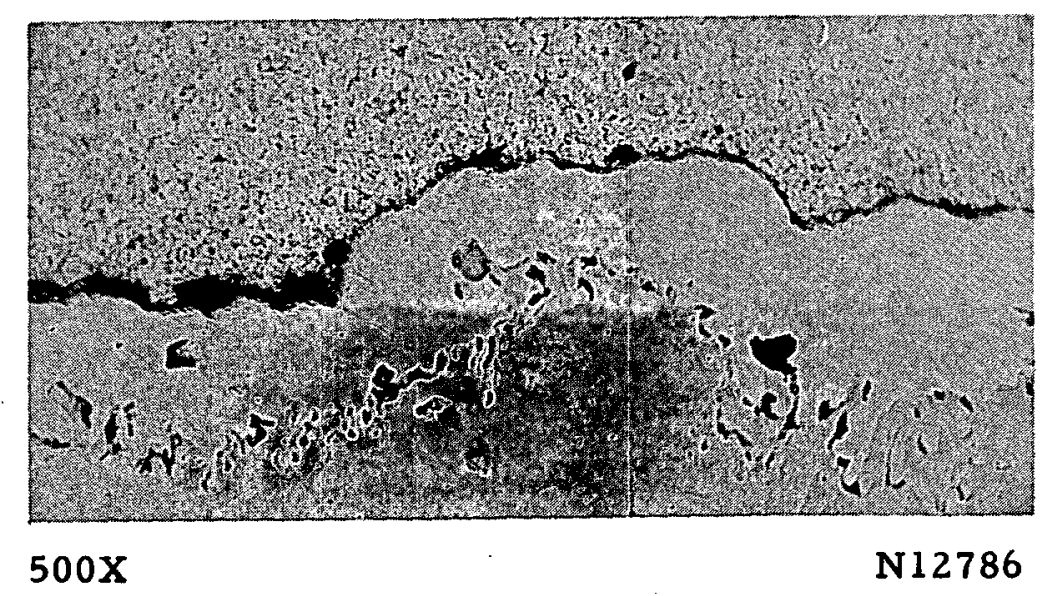

FIGURE 16. ALUMINUM-URANIUM EDGE BOND WITH NICKEL INTERFACE Rolled at $1100 \mathrm{~F}$ Through Grooved Rolls

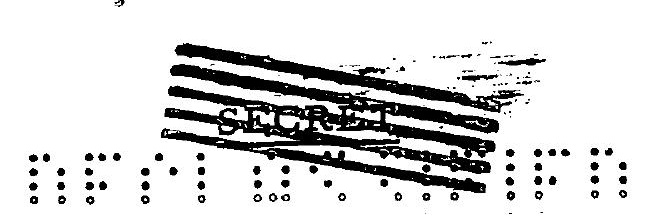

3 


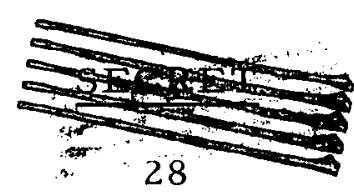

Only one method has been tried. It involved the use of grooved rolls with angled groove edges for side pressure. The two rolls were grooved $0.100 \mathrm{in}$. deep. The total effective thickness of the pack is $0.220 \mathrm{in}$. (two $0.020-i n$. cover plates and a 0.18-in. core). This thickness allows a maximum reduction of 9 per cent when the rolls are closed. The grooves are narrower than the sheath and the edges are tapered 35 deg to give side pressure.

A series of sheathed cores was rolled through these grooves at 900 and $1100 \mathrm{~F}$, with 4 and 5 per cent reductions. Metallographic examination showed that there was good edge bonding in the packs rolled at $1100 \mathrm{~F}$, but there were quite a few localized voids in the edges of the packs rolled at $900 \mathrm{~F}$. A cross section of one of the edges is shown in Figure 16. This plate, rolled at $1100 \mathrm{~F}$, had good edge bonding. The plates rolled very well and showed no evidence of seizing in the grooves. They were not flat, however; a flattening operation will be required to prepare them for use.

Another method of applying side pressure is with edger rolls. Such rolls are mounted perpendicular to the rolls in the mill, in the same plane. Since such equipment is not available at Battelle, this rolling method was not tried. From all indications, however, edger rolls would be well suited for such rolling.

More promising than the edger rolls is the Turk's Head roll. This is actually an adaptation of edger rolls. The rolls are mounted in the same way, but none of them is powered. The Turk's Head is usually mounted on a draw bench and the plate is drawn through. The front tension tends to maintain a flat plate and eliminate the necessity of a flattening operation. Front tension also lowers the peak of the roll-distribution curve considerably (3). There is a possibility that this lowering would tend to increase the difference in reduction between the pack and the core. If the peak pressure could be maintained below the yield strength of the uranium core, all of the deformation would occur in the clad. Such a rolling operation would be ideal if beta-quenched cores were used.

\section{CONCLUSIONS}

The results of these experiments indicate that the flat-plate fuel elements can be prepared by a rolling-type operation. However, considerable work is still necessary to perfect such a process and to adapt it to largescale production.

Several problems must be solved. The best end bonds were obtained with cgpper-plated end plugs. The use of copper oplate necessitated rolling 
below the copper-aluminum eutectic, $1018 \mathrm{~F}$. A rolling range from 950 to $1000 \mathrm{~F}$ could be used, but this temperature is apparently below the alpharolling stability range. Therefore, bonding has to be accomplished with a minimum of reduction to maintain either a stable alpha or a beta-quenched structure. Another significant deterrent to the use of copper-plated end plugs, and hence a lower rolling temperature, was that the best core-tocladding bonding with a nickel interface was obtained at a roll temperature of $1100 \mathrm{~F}$. The use of copper plate on the end plugs as well as on the core would eliminate some of these problems, but it would most likely be undesirable for its effect on corrosion.

Edge bonding was also not as effective at the lower temperatures as it was at $1100 \mathrm{~F}$. Perhaps this differential could be eliminated by the use of edge rolls, which probably would exert more side pressure than is possible with tapered grooved rolls.

In rolling of full-size plates, there is also the problem of protecting the mating surfaces during the preheat. The leading end of the assembly is sealed by pressure bonding, but the trailing end is open. The interior of the assembly must be protected from oxidation if clean bonds are to be formed. A protective atmosphere may be undesirable since any entrapped gas will not be absorbed by the metals and voids will result. It may be possible to evacuate the assemblies and to bond the trailing end only along the end, to produce a tight assembly during heating. On rolling, the force of the extruding aluminum sheath would rupture this bond, and the sheath would flow over the trailing end of the core. The excess aluminum could be sheared, and, to assure closure, the trailing end would be pressure bonded.

\section{REFERENCES}

(1) Metals Handbook, 1948 Edition, American Society for Metals, p 790.

(2) Cawthorne, E. W., Craighead, C. M., Berry, W. E., Pray, H. A., and Jaffee, R. I., "A Study of the Dip Coating of Uranium Sheet With Aluminum-Silicon Alloy", BMI-896 (January 18, 1954).

(3) Underwood, L. R., The Rolling of Metals, Chapman and Hall, London (1950), p 199.

HAS:SJP:JFD / mlg

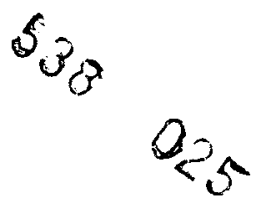

